Article

\title{
Liquidity Risk and Investors' Mood: Linking the Financial Market Liquidity to Sentiment Analysis through Twitter in the S\&P500 Index
}

\author{
Francisco Guijarro *D, Ismael Moya-Clemente and Jawad Saleemi \\ Business School, Universitat Politècnica de València, 46022 Valencia, Spain; imoya@esp.upv.es (I.M.-C.); \\ j.saleemi@yahoo.com (J.S.) \\ * Correspondence: fraguima@upvnet.upv.es; Tel.: +34-96-387-7000
}

Received: 8 November 2019; Accepted: 5 December 2019; Published: 10 December 2019

check for updates

\begin{abstract}
Microblogging services can enrich the information investors use to make financial decisions on the stock markets. As liquidity has immediate consequences for a trader's movements, this risk is an attractive area of interest for both academics and those who participate in the financial markets. This paper focuses on market liquidity and studies the impact on liquidity and trading costs of the popular Twitter microblogging service. Sentiment analysis extracted from Twitter and different popular liquidity measures were gathered to analyze the relationship between liquidity and investors' opinions. The results, based on the analysis of the S\&P 500 Index, found that the investors' mood had little influence on the spread of the index.
\end{abstract}

Keywords: social media; opinion mining; financial market liquidity; sentiment analysis; trading costs

\section{Introduction}

Sentiment analysis is a field of natural language processing (NLP) that aids in understanding and extracting different opinions on a given subject. As 2.5 quintillion bytes of data are generated daily all over the world by the participants of social media, sentiment analysis tools can be used to make sense of the data. While opinion mining categorizes opinions into positive or negative, sentiment analysis is a field of interest for both academics and practitioners, since the constantly expanding social networks enable the exchange of information and opinions on products, services or any other subject. Sentiment analysis not only transforms such unstructured public information into structured data, but also makes it possible to apply the data to various areas, such as customer feedback, product/service reviews, net promoter scoring, stakeholder relations, marketing, financial market predictions, or almost any other field.

Social media are cost-effective and easily available networks that exchange information for both private and business purposes while eradicating geographical barriers. They are a broad source of co-creation values in which the participants contribute to evaluating and refining conceptualizations [1].

Social media can be divided into six types [1]: Social networking sites, blogs and micro blogs, collaborative projects, virtual game worlds, content communities, and virtual communities. This categorization has contributed a great deal to expanding the literature of social media into diverse notable fields, such as polling estimation [2,3], tourism [4], medicine and healthcare [5,6], collaborative learning [7], social participation [8], sport [9], communication [10], organizing [11], recruiting/selection decisions [12], crisis event analysis [13-15], public-spending review [16], and stock market predictions related to returns, prices, volatility, and trading volume [17-19].

To the authors' knowledge, however, the impact of social media on financial market liquidity and thus on trading costs has not been explored. Market liquidity facilitates the efficient and stable 
functioning of financial markets [20]. It is a multi-dimensional concept, generally referring to the immediacy of the execution of a trade with a limited price impact and low transaction costs [21]. While various of its aspects can be studied, this study investigates whether the Twitter microblogging social network influences liquidity.

The financial crisis of 2007-2009 crucially underlined the significance of liquidity on the functioning of the global financial markets [20]. The severe trading losses led the major players in the financial system to reassess their risk profiles and business models, which was considered a major step towards the implementation of rigorous regulatory reforms throughout the financial sector. Policy makers emphasized the need to constrain the banks' riskier business lines, such as investment banking and trading [22]. There has been a measurable reduction in banks' trading capacity: Bank holdings of trading assets have dropped by more than $40 \%$ between 2008 and 2015. However, concerns are growing on their willingness and ability to take risks as market makers or whether they would withdraw abruptly in cases of liquidity distress.

Financial market liquidity can be suddenly reduced for several reasons. Firstly, it depends in part on the transparency of information on security values, which vary over time. Secondly, the number of liquidity providers and their access to capital is a significant determinant of market liquidity. Thirdly, increased uncertainty about market liquidity makes the provision of liquidity riskier and increases the compensation that liquidity providers demand, i.e., the trading cost (bid-ask spread) increases.

The existing literature argues that asymmetric information is one of the factors in determining the liquidity and trading cost [23-26]. Social media have constructed a diversified structure of social networks, in which the participants, irrespective of their professional background, are open to exchanging information on financial markets and certain securities as a whole. It is therefore essential to investigate the impact of such information and opinions on financial market liquidity.

The aim of this paper is thus to analyze the impact of social media on financial market liquidity. This analysis can have potential implications for both academics and investors in terms of quantifying social media-based sentiments towards financial market liquidity and trading costs.

The rest of the paper is structured as follows. A brief survey of the literature is included in Section 2. A description of the data collected and different liquidity measures is given in Section 3 . The research results are presented and discussed in Section 4 and the paper ends with the main conclusions highlighted in Section 5.

\section{Review of the Literature}

Market participants evidently generate spaces within products, services and firms by reflecting opinions and concerns [27], which further develops the field of communications [28]. Social media have not only contributed to revolutionizing reciprocity between stakeholders and businesses, but have also changed the approach of business-related content with regard to production, distribution and consumption [27]. Firms have cost-effective opportunities to communicate and build a strong relationship with stakeholders through social networking [29] without distance and geographical barriers [30].

Firms engagement in social media can build up direct relationships with customers, expand business by identifying new opportunities, create their product-related communities, collect opinions and concerns and generally improve gaps [31]. Due to their non-transactional nature, social media are well suited to collecting feedback from a very large potential audience, initiating two-way communications and developing relationships with customers through interaction [1] and are therefore a cost-effective source of targeting an immense audience and gathering large volumes of feedback.

Twitter, as a microblogging social network, is one of the most popular communication sources through which participants can interact globally with messages known as 'tweets'. Besides facilitating private communications between the participants, Twitter also distributes information on professional contexts, for example financial market-related groups, such as StockTwits, Financial Times, 
Market-Watch, etc. That prompt investors to share their opinions on investment in financial markets and certain securities [32]. There are around 313 million active users of Twitter who interact with tweets in more than 40 languages. The influential role of Twitter has been revealed in various fields such as election results and political debates [33,34], academic communications [35], brand reputations [36], stock volatility, returns and volumes [18], and portfolio returns [19].

Financial market analysis is one of the most attractive areas in the literature on market microstructures-it is concerned with the details of how exchanges occur in the market by means of various theories. The chartist theory suggests that patterns and trends of its past behaviour tend to recur in the future and provides future asset prices based on historical data. The random walk theory argues that asset prices evolve randomly and cannot be predicted from historical patterns and stock market trends, so that prices are identical independent variables.

Besides such assumptions, variations in asset prices can be influenced by the media [37-41]. Public opinions through social media can significantly influence the investment decision-making proces [42] and have an impact on the financial market. The social media have been extensively examined by researchers in order to determine the state of the financial market at both the indicator and firm levels $[17,18,43-45]$. These studies use sentiment analysis tools to extract opinions and information in terms of binary sentiment results (positive or bullish vs negative or bearish) or multi-level sentiment results. Some recent works are focused on the relationship between social media and market behaviour. A good example is [46], who analyze how social media impact financial markets, which is different if we compare it with traditional sources of investor attention such as newspapers, analyst coverage, earnings announcements, and business news wires. They show that "increases in Twitter activity are associated with positive abnormal returns and, when occurring in conjunction with traditional information supply events, increase the diffusion of information to investors". Authors also introduce an interesting difference between the supply of information (Tweeter activity) and the consumption of information (retweet activity), and show that the consumption of information increases the magnitude of the price impact. In a similar way, reference [47] study whether social media can provide new insights on market panics and manias that are not already captured by traditional data. They show that highly abnormal social media sentiment—as measured by Twitter and StockTwits messages—is preceded by very strong momentum and followed by mean-reverting return. Authors design a strategy based on this mean-reverting effect which outperforms a benchmark mean-reversion strategy that does not use social-media data. Other areas where social media are related with financial markets include IPO performance [48], information asymmetry [49], market manipulation [50] and communication of financial information [51].

As previously stated, investors' sentiments may be reflected by the financial markets $[17,37,40]$. Positive sentiments cause asset prices and returns to rise, while negative sentiments may reduce them. It is therefore of interest to apply sentiment analysis tools to investors' sentiments, which not only show investors' emotions based on their perceptions but also investigate their impact on financial market forecasting.

The existing literature often uses Pearson correlation coefficients [32,45,52] and beta coefficients of linear regression models $[17,44,53]$ to examine the relationship between the financial market and investors' sentiments. Most of the existing literature indicates the positive relationship between social media and the financial market $[17,32,44,52,54]$, but limited to certain aspects such as prices, returns, volatility or trading volume [17-19,32,37,42-45,52,53].

Liquidity is a time-varying risk factor [55]. The risk arises in situations in which a share cannot be traded quickly enough to prevent or minimize a loss. The liquidity risk, in general, is considered the centre of any financial crisis [20]. Liquidity tends to be highly volatile, which means that it can vanish within minutes. It has become an important issue for traders and can even cause a systemic risk. Due to the severe consequences of an evaporation of liquidity in securities and funding markets during a potential financial crisis, the systemic liquidity risk should be closely monitored [20]. 
Market participants who seek to make an immediate trade would possibly trade at the best available price, i.e., the bid price if buying or the asking price if selling. The bid-ask spread has gained huge interest among market participants due to the fact that it is a significant measure of trading costs and thus a proxy for financial market liquidity [20,56-59]. The size of the spread reflects an asset's liquidity, i.e., the ease and cost of trading an asset.

The literature concentrates on three factors-adverse selection costs [23-26], inventory holding costs [56,60-62] and order processing costs [63] —in order to determine the bid-ask spread. Reference [57] developed a three-way decomposition model by combining the spread components-order processing, adverse selection and inventor holding costs-and disclosed the significance of these components in estimating the true spread.

When securities become information-sensitive, the financial markets are not perceived as liquid [64]. This causes an adverse selection problem: informed optimistic investors would buy an asset even at a higher ask-price, while pessimistic sellers have an incentive to sell at a lower bid-price. Traders with private information on the fundamental value of securities would consider the price effect of their trades, and market makers are likely to protect themselves against informed traders, so that reduced liquidity produces a wider bid-ask spread.

In addition to private information on the fundamental value of an asset, the literature also illuminates the significance of private information on order flows $[65,66]$. For example, if a trading desk foresees that a hedge fund will liquidate a huge position which will likely depress prices, then the trading desk will sell early while the price is high and buy back later at a lower price. Informed buyers have incentives in large trades, which increase dealers' potential losses so that dealers would widen the spread.

The bid-ask spread is a compensation for dealers who offer immediacy while accepting the risk of holding an inventory. Dealers are risk aversion agents that facilitate liquidity in the market while optimizing their own security portfolios. In fact, all the buyers are not present in the market at all times, so this gap between buyer and seller is bridged by market makers, who may buy a security in anticipation of being able to resell it to the buyer. However, market makers take into account the risk of price fluctuations in the meantime and would be compensated for this risk in terms of imposing a cost on the seller, i.e., a higher spread. Additionally, the spread compensates dealers who offer immediacy by bearing some of the fixed costs. Consistent with the empirical literature, reference [67] showed that the bid-ask spread is a positive function of the price level and return variance, a negative function of measures of market activity, depth, and continuity, and negatively correlated with the degree of competition. The illiquidity premium was documented for the equity market in [56], while [68] measured the effective bid-ask spread by using the first-order serial covariance of price changes. Later, reference [25] developed a technique for estimating a model that decomposed the bid-ask spread into two components, one due to asymmetric information and one due to inventory costs, specialist monopoly power, and clearing costs.

\section{Data Sampling and Methodology}

This paper studies the impact of microblogging data (tweets) on the market liquidity of the S\&P500 Index, and as a result, on the transaction cost associated with trading, that is the bid-ask spread. This not only captures the trading cost, but is also a true measure of actual market liquidity, which can be measured in various ways. Based on the theoretical foundation of market liquidity, we apply various liquidity measures including (1) high-low difference, (2) spread derived by [25], (3) quoted spread, and (4) effective spread.

The liquidity measures applied in this study are standard and have previously been examined in different aspects of the asset pricing literature, although all liquidity measures and indices are in fact the proxies for illiquidity [69]. Investors take the significance of financial market liquidity into consideration at the time of decision-making because it is a great indicator of the efficiency of financial markets. The literature on the market microstructure proposes and constructs the bid-ask spread in 
several ways. The bid-ask spread simply is defined as the difference between the seller's asking price for an asset and the bid price offered by the buyer. The high or ask price refers to the highest price during the trading day, whereas the low or bid price is defined as the lowest price during the same day. A spread can be computed by using the daily high and low prices, which is given by:

$$
S=\operatorname{High}_{t}-\text { Low }_{t}
$$

An alternative liquidity measure of daily high and low prices was derived by [25], who considers that any transaction discloses something about a trader's private information. The bid-ask spread was modelled in the following manner:

$$
\text { GMS }=A s k_{t}-B i d_{t}
$$

The expected value of the security conditional on a trade at: $A s k_{t}=v^{H} \pi+\bar{v}(1-\pi)$, and where bid price is assumed by: $B i d_{t}=v^{L} \pi+\bar{v}(1-\pi) \cdot v^{H}$ and $v^{L}$ are high and low possible values, respectively, for an asset with equal probability. An informed optimistic trader is present with probability $\pi$. Assuming risk neutrality, uninformed pessimistic traders value the security at $\bar{v}=\frac{\left(v^{H}+v^{L}\right)}{2}$. The model assumes that the spread would be greater in case of a higher probability of trading with an informed trader.

The quoted spread (QS) and effective spread (ES) are the most common measures of market liquidity and significantly explain the spread context. The quoted spread is simply the difference between the ask (high) quote and the bid (low) quote at a given time in the market, divided by the average of the two quotes (mean of $\mathrm{High}_{t}$ and $\mathrm{Low}_{t}$ ):

$$
Q S=\frac{\operatorname{High}_{t}-\operatorname{Low}_{t}}{M_{t}}
$$

By taking into consideration the hidden orders, order internalization by market-makers, the effective spread is considered a leading measure of financial market liquidity, which is defined as the absolute value of the difference between the trade price, $P_{t}$, and the midpoint of the quotes, $M_{t}=$ $\left(\frac{\text { High }_{t}+\text { Low }_{t}}{2}\right)$, divided by the mean of Hight and $\operatorname{Low}_{t}$ :

$$
E S=\frac{2\left|P_{t}-M_{t}\right|}{M_{t}}
$$

The data used in this research was obtained from the Center for Research in Security Prices, which contains daily observations of high, low, and closing prices. The dataset therefore has both time and individual dimensions. To understand the impact of microblogging data on financial market liquidity and trading costs, the study took into consideration tweets, consisting of 23,008 observations, related to the S\&P500 Index and collected daily during the period 3 July 2019-1 October 2019. The analysis was carried out on R programming software, in which the machine learning strategy and a linear regression model are applied to disentangle the various aspects involved. The machine learning strategy was used to extract the aggregated sentiments, while the regression model used sentiments as the independent variable and the abovementioned liquidity measures as the dependent variables. Hence, we used four regression models to analyze the link between investors' mood and liquidity of the S\&P Index as shown in Equation (5):

$$
\text { Liquidity }_{t}=\alpha+\beta_{1} \text { Sentiments }_{t}+\epsilon_{t}
$$

where Liquidity $t$ corresponds to each liquidity measure of Equations (1)-(4) in $t$, Sentiments $s_{t}$ represents the extracted sentiment for that period, and $\epsilon_{t}$ is the error term. The regression model was performed by using the ordinary least squared technique (OLS), and no control variables were included in the process. 
In order to construct the 'Sentiments' variable from unstructured data (tweets), we executed some pre-processing tasks using the software R. At the first stage, $\mathrm{R}$ served to clean each tweet by removing punctuation and stop words, converting words into lower case, striping any leading or trailing spaces and for privacy reasons, setting all participants' addresses into '@user'. At the final stage, $R$ categorizes each structured tweet into a numerical positive or negative value between -5 and 5 that defines the importance of a tweet with positive scores indicating positive sentiment and negative scores indicating negative sentiment on a given day. For example, the most positive sentiment got a score of 4.75 from the tweet "Watch it! An amazing truth. How the brain works. If you like it Share it Please Awesome information SP\&500 \#amazing \#unbeliev", and the most negative sentiment was valued at -3.9 from the tweet "In a pathetic attempt to avoid panic selling S\&P; a stock market crash, the Trump administration wasted $\$ 130$ billion of tax". Figure 1 shows the distribution of each tweet sentiments throughout the analysed period. The Box-plot distribution indicates both positive and negative sentiments, in which most of the market participants can be viewed as bullish.

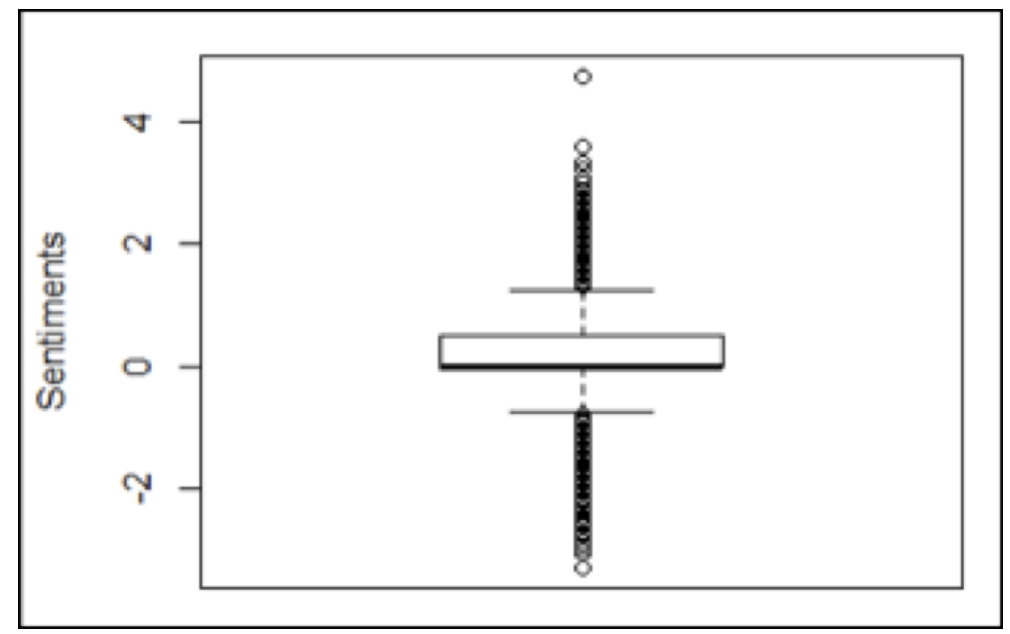

Figure 1. Bullish vs bearish.

\section{Research Findings and Discussion}

The descriptive statistics of the variables, liquidity measures and aggregated sentiments, for the data sample are presented in Table 1, which shows significant differences among the applied bid-ask spreads. As can be seen in Table 1, the variables are positively skewed, which indicates the right-skewed distributions of variables with values to the right of their mean, whereas higher variable kurtosis represents the possibility of extreme values.

Table 1. Descriptive statistics of variables for the data sample.

\begin{tabular}{cccccc}
\hline & $S$ & GMS & $Q S$ & ES & Sentiments \\
\hline Min & 9.030 & 4.520 & 0.002997 & 0.000040 & -6.950 \\
Median & 22.77 & 11.39 & 0.007764 & 0.004452 & 44.70 \\
Mean & 27.69 & 13.84 & 0.009410 & 0.005359 & 42.32 \\
Max & 92.04 & 46.02 & 0.031950 & 0.023520 & 101.6 \\
Std. Dev. & 17.21 & 8.600 & 0.005982 & 0.004918 & 21.53 \\
Skewness & 1.729 & 1.729 & 1.766 & 1.382 & 0.125 \\
Kurtosis & 5.966 & 5.966 & 6.143 & 5.173 & 3.396 \\
\hline
\end{tabular}

The liquidity and sentiment measurements are shown in the graph in Figures 2 and 3, respectively. The time-series plots presented in Figure 2 clearly disclose differences between the computed liquidity. 

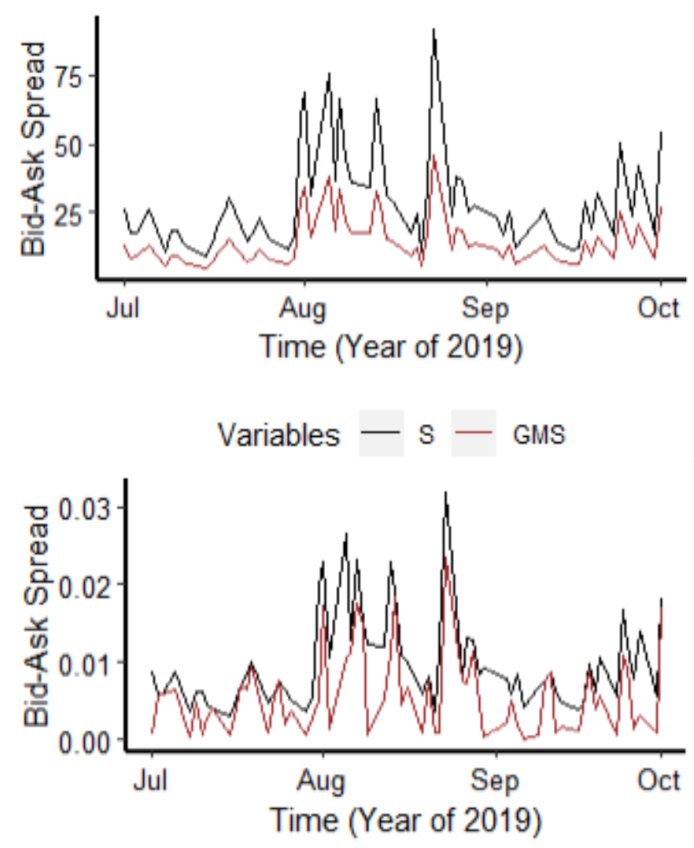

Variables - QS - ES

Figure 2. Time-variations in financial market liquidity.

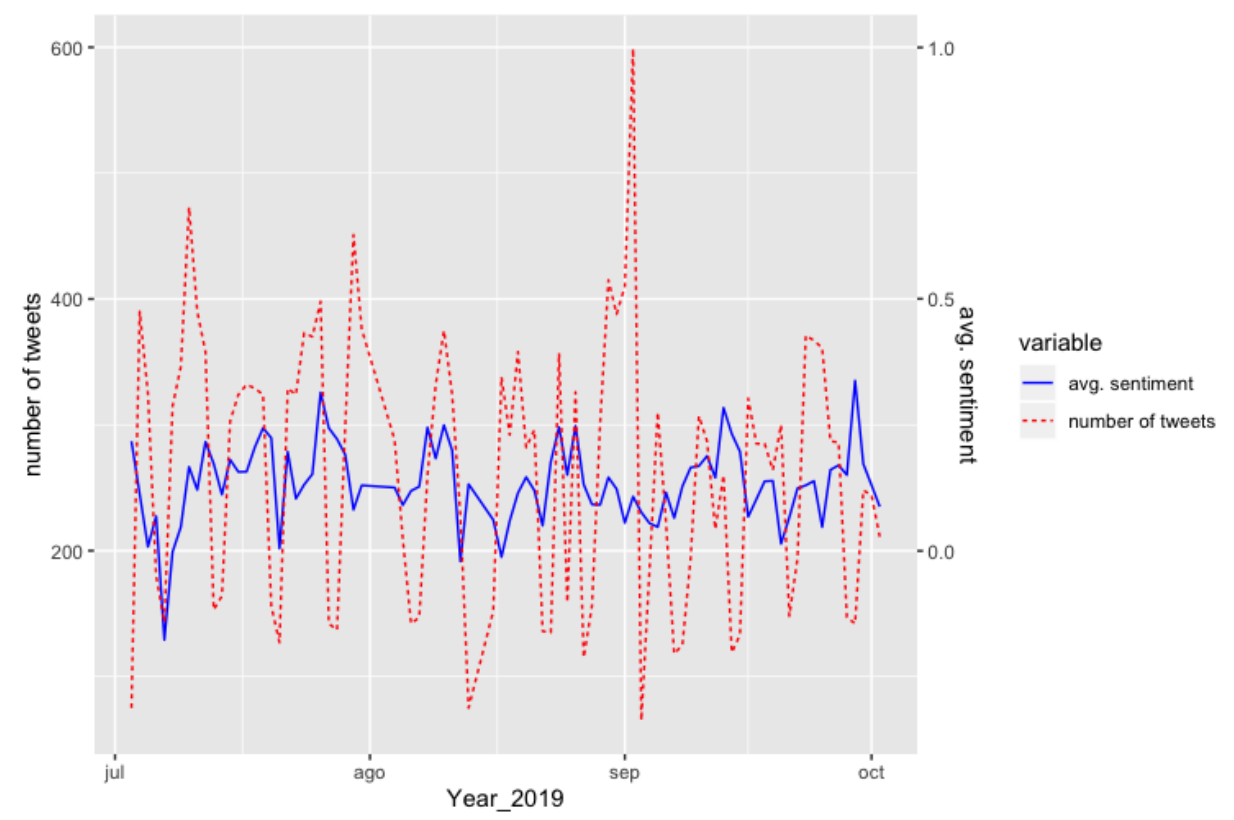

Figure 3. Time-variations in sentiments average and the number of tweets per day.

We have performed an autocorrelation analysis to study whether the time series are linearly related to lagged versions of themselves. Figure 4 shows the autocorrelation plot for each liquidity measure. We observe that values are within $95 \%$ confidence interval (represented by the dashed blue line) for lags $>1$, but lag $=1$ falls outside this confidence interval. So that, we can conclude that all liquidity measures are serially correlated, and this must be considered in the regression models by including the lagged computation of the liquidity measure (Equation (6)).

$$
\text { Liquidity }_{t}=\alpha+\beta_{1} \text { Sentiments }_{t}+\beta_{2} \text { Liquidity }_{t-1}+\epsilon_{t}
$$


Series S

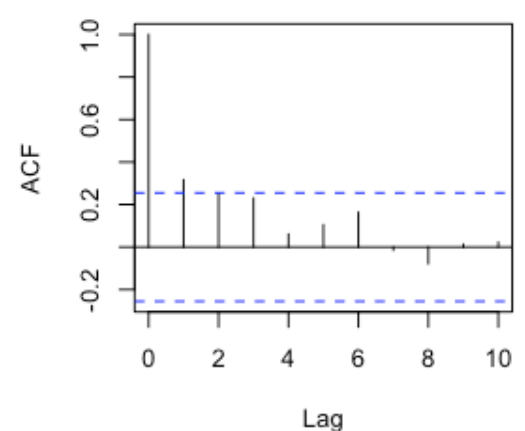

Series QS

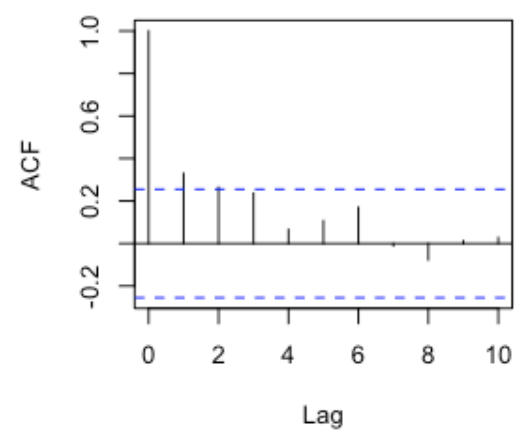

Series GMS

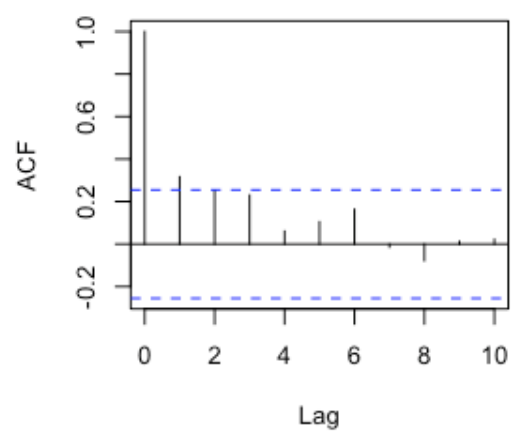

Series ES

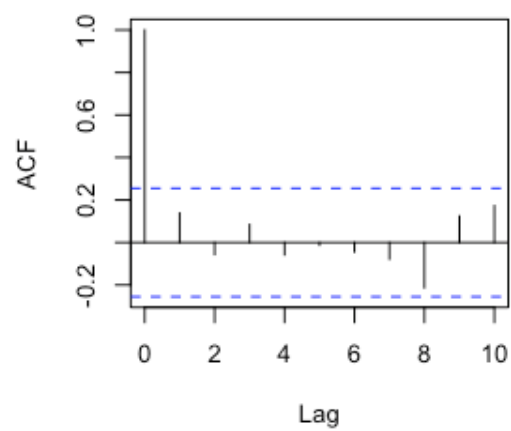

Figure 4. Autocorrelation plot for liquidity measures.

The correlation coefficients between liquidity measures, shown in Table 2, are highly correlated. This implies that the applied liquidity measures significantly respond to any variations in market liquidity over time. Figure 3 shows the evolution of the sentiment average regarding the S\&P500 index along with the daily number of tweets collected. It has been observed that the sentiments are not constant and change over time, while something similar happens to the number of tweets. However, no clear relationship can be found between the average sentiment and the number of tweets. We analysed the relationship between these time-variations in sentiments and liquidity by means of a regression analysis.

Table 2. Linear correlation coefficients for the liquidity measures.

\begin{tabular}{ccccc}
\hline & $S$ & GMS & QS & ES \\
\hline$S$ & 1.000 & 1.000 & 0.999 & 0.790 \\
GMS & 1.000 & 1.000 & 0.999 & 0.790 \\
$Q S$ & 0.999 & 0.999 & 1.000 & 0.791 \\
ES & 0.790 & 0.790 & 0.791 & 1.000 \\
\hline
\end{tabular}

Table 3 shows the coefficients obtained through a linear regression where sentiments average, "Sent", is the independent variable and each liquidity measure is considered as the dependent variable. The lagged liquidity measure has been also included to control for autocorrelation (Equation (6)) .

The regression analyses notably reveals that the coefficients associated to sentiments, $\beta_{1}$, are positive in each dataset but not significant. This indicates that any changes in investors' perceptions are very weakly correlated to variations in financial market liquidity and trading costs. $R$-Squared, $p$-values, and F-statistics in Table 3 further explain that a much lower proportion of the changes in market participants' perceptions affect the time-varying liquidity and trading cost for each dataset. These results were obtained after controlling for autocorrelation. In addition, we have checked the 
residuals of all regression models. The Kolmogorov-Smirnov test shows that residuals are not normally distributed except for the ES liquidity measure ( $p$-value $=0.421)$. Heteroscedasticity was also checked. In this case, the Breusch-Pagan test showed that residuals were homoscedastic for all regressions.

Table 3. Regression Analysis.

\begin{tabular}{cccc}
\hline & & Estimate & $p$-Value \\
\hline \multirow{3}{*}{$S(1)$} & Intercept & 18.676 & $0.001^{* *}$ \\
& Sentiments & 0.005 & 0.960 \\
& $S_{t-1}$ & 0.329 & $0.015^{*}$ \\
\hline \multirow{3}{*}{ GMS (2) } & Intercept & 9.338 & $0.001^{* *}$ \\
& Sentiments $^{*}$ & 0.002 & 0.960 \\
& GMS $_{t-1}$ & 0.329 & $0.015^{*}$ \\
\hline \multirow{3}{*}{ QS (3) } & Intercept & 0.006 & $0.002^{* *}$ \\
& Sentiments & 0.000 & 0.976 \\
& QS $_{t-1}$ & 0.342 & $0.011^{*}$ \\
\hline \multirow{3}{*}{ ES (4) } & Intercept & 0.003 & $0.042^{*}$ \\
& Sentiments & 0.000 & 0.212 \\
& ES & 0.115 & 0.419
\end{tabular}

(1) Adjusted $R$-squared: 0.073,F-statistic: 3.232, $p$-value: 0.047; (2) Adjusted $R$-squared: $0.073, F$-statistic: 3.232 , $p$-value: 0.047; (3) Adjusted $R$-squared: 0.082, F-statistic: 3.539, $p$-value: 0.036; (4) Adjusted $R$-squared: 0.014, F-statistic: $1.411, p$-value: 0.252 ; Signif. codes: ${ }^{\prime * * * \prime}<0.001{ }^{\prime * * *^{\prime \prime}}<0.01 ;^{\prime * \prime}<0.05$.

These results only discount the relation between investors' sentiments and financial liquidity on a daily basis. In other words, it seems that the liquidity on a given trading day is not related to the investors' sentiments collected from tweets. The following experiment was constructed on a two-day basis: we computed the two-day moving average for each considered liquidity measure and the sentiment score to analyse whether the relation between the computed liquidity measures and sentiments was not only observed at one point in time, but was constructed over a period of time. Investors may need extra time to analyse social media's mood and then use this information, not necessarily on the same day, but also during the following trading sessions.

Table 4 gives the regression statistics for each dataset applied in the study. The regression estimates are again positive in each dataset, but their relationship reflects that changes in investors' mood are very weakly effective in determining the size of the bid-ask spread. In all regressions the improve in the $R^{2}$ comes from the inclusion of the lagged liquidity measure. However, the coefficient of sentiments with the ES liquidity measure is statistically significant even after controlling for autocorrelation, which implies that investors' mood and the liquidity of the S\&P500 Index are related on a two-day basis. This gives a new insight into the relation between these two variables, which will be analysed in a further study with a larger database and different financial assets to those considered here. Residuals of all regression models have been also checked. The Kolmogorov-Smirnov and Breusch-Pagan tests show that residuals are normally distributed and homoscedastic in all cases.

Table 4. Regression analysis based on two-days moving average of liquidity.

\begin{tabular}{cccc}
\hline & & Estimate & $p$-Value \\
\hline \multirow{3}{*}{$S(1)$} & Intercept & 6.119 & 0.114 \\
& Sentiments & 0.044 & 0.479 \\
& $S_{t-1}$ & 0.715 & $0.000^{* * *}$ \\
\hline \multirow{3}{*}{ GMS (2) } & Intercept & 3.059 & 0.114 \\
& Sentiments & 0.022 & 0.479 \\
& GMS $_{t-1}$ & 0.715 & $0.000^{* * *}$ \\
\hline
\end{tabular}


Table 4. Cont.

\begin{tabular}{cccc}
\hline & & Estimate & $p$-Value \\
\hline \multirow{4}{*}{$Q S(3)$} & Intercept & 0.002 & 0.129 \\
& Sentiments & 0.000 & 0.484 \\
& $Q S_{t-1}$ & 0.723 & $0.000^{* * *}$ \\
\hline \multirow{2}{*}{ ES (4) } & Intercept & 0.001 & 0.404 \\
& Sentiments & 0.000 & $0.047^{*}$ \\
& $E S_{t-1}$ & 0.515 & $0.000^{* * *}$ \\
\hline
\end{tabular}

(1) Adjusted $R$-squared: 0.505, F-statistic: 29.576, $p$-value: 0.000; (2) Adjusted $R$-squared: 0.505, F-statistic: 29.576, $p$-value: 0.000; (3) Adjusted $R$-squared: 0.516, F-statistic: 30.892, $p$-value: 0.000; (4) Adjusted $R$-squared: 0313, F-statistic: $13.793, p$-value: 0.000; Signif. codes: ${ }^{* * * \prime}<0.001 ;^{(* * \prime}<0.01 ;^{(* \prime}<0.05$.

\section{Conclusions}

In this study we analysed the impact of investors' mood on market liquidity and on the costs associated with trading. We performed a sentiment analysis of tweets related to the S\&P500 Index and considered four different measures of liquidity. On a daily basis, we found that even though the regression estimates are positive, they are not statistically significant. However, if a two-day moving average is computed on all the variables concerned, the results are slightly improved. The investors' mood was found to be positive and significantly related to the effective spread of the liquidity measure.

Our findings should encourage other researchers to make additional efforts to study a larger dataset by widening the analysed period and including new assets. In the present study we only investigated the S\&P500 Index, which is limited to concluding in a broader sense that Twitter, as a source of information, has little influence on any changes that occur in the size of spread and time-varying liquidity. There is thus a great need for future research in this area to study the relationship between microblogging data and market liquidity at the sector and firm levels. This would undoubtedly help us to understand the significance of microblogging data on financial market liquidity and trading costs in a broader sense.

Author Contributions: Conceptualization, J.S.; methodology, F.G., I.M.-C. and J.S.; software, J.S.; validation, F.G. and I.M.-C.; resources, J.S.; data curation, J.S.; writing—original draft preparation, J.S.; writing-review and editing, F.G., I.M.-C. and J.S.; supervision, F.G. and I.M.-C.

Funding: This research received no external funding.

Conflicts of Interest: The authors declare no conflict of interest.

\section{References}

1. Kaplan, A.M.; Haenlein, M. Users of the world, unite! The challenges and opportunities of Social Media. Bus. Horiz. 2010, 53, 59-68. [CrossRef]

2. O'connor, P. Managing a hotel's image on TripAdvisor. J. Hosp. Mark. Manag. 2010, 19, 754-772. [CrossRef]

3. Ceron, A.; Curini, L.; Iacus, S.M. Using sentiment analysis to monitor electoral campaigns: Method matters-Evidence from the United States and Italy. Soc. Sci. Comput. Rev. 2015, 33, 3-20. [CrossRef]

4. Zeng, B.; Gerritsen, R. What do we know about social media in tourism? A review. Tour. Manag. Perspect. 2014, 10, 27-36. [CrossRef]

5. Grajales, F.J., III; Sheps, S.; Ho, K.; Novak-Lauscher, H.; Eysenbach, G. Social media: A review and tutorial of applications in medicine and health care. J. Med. Internet Res. 2014, 16, e13. [CrossRef]

6. Adams, S.A.; Van Veghel, D.; Dekker, L. Developing a research agenda on ethical issues related to using social media in healthcare: Lessons from the first Dutch Twitter heart operation. Camb. Q. Healthc. Ethics 2015, 24, 293-302. [CrossRef]

7. Zhang, X.; Wang, W.; de Pablos, P.O.; Tang, J.; Yan, X. Mapping development of social media research through different disciplines: Collaborative learning in management and computer science. Comput. Hum. Behav. 2015, 51, 1142-1153. [CrossRef] 
8. Boulianne, S. Social media use and participation: A meta-analysis of current research. Inf. Commun. Soc. 2015, 18, 524-538. [CrossRef]

9. Filo, K.; Lock, D.; Karg, A. Sport and social media research: A review. Sport Manag. Rev. 2015, 18, $166-181$. [CrossRef]

10. McFarland, L.A.; Ployhart, R.E. Social media: A contextual framework to guide research and practice. J. Appl. Psychol. 2015, 100, 1653. [CrossRef]

11. Leonardi, P.M.; Vaast, E. Social media and their affordances for organizing: A review and agenda for research. Acad. Manag. Ann. 2017, 11, 150-188. [CrossRef]

12. Roth, P.L.; Bobko, P.; Van Iddekinge, C.H.; Thatcher, J.B. Social media in employee-selection-related decisions: A research agenda for uncharted territory. J. Manag. 2016, 42, 269-298. [CrossRef]

13. Pope, D.; Griffith, J. An Analysis of Online Twitter Sentiment Surrounding the European Refugee Crisis. In Proceedings of the International Joint Conference on Knowledge Discovery, Knowledge Engineering and Knowledge Management, Porto, Portugal, 12-14 November 2016; pp. 299-306.

14. Shaikh, S.; Feldman, L.B.; Barach, E.; Marzouki, Y. Tweet sentiment analysis with pronoun choice reveals online community dynamics in response to crisis events. In Advances in Cross-cultural Decision Making; Springer: Berlin/Heidelberg, Germany, 2017; pp. 345-356.

15. Öztürk, N.; Ayvaz, S. Sentiment analysis on Twitter: A text mining approach to the Syrian refugee crisis. Telemat. Inform. 2018, 35, 136-147. [CrossRef]

16. Agostino, D.; Arena, M.; Catalano, G.; Erbacci, A. Public engagement through social media: The spending review experience. Public Money Manag. 2017, 37, 55-62. [CrossRef]

17. Bollen, J.; Mao, H.; Zeng, X. Twitter mood predicts the stock market. J. Comput. Sci. 2011, 2, 1-8. [CrossRef]

18. Oliveira, N.; Cortez, P.; Areal, N. The impact of microblogging data for stock market prediction: Using Twitter to predict returns, volatility, trading volume and survey sentiment indices. Expert Syst. Appl. 2017, 73, 125-144. [CrossRef]

19. Bank, S.; Yazar, E.E.; Sivri, U. Can social media marketing lead to abnormal portfolio returns? Eur. Res. Manag. Bus. Econ. 2019, 25, 54-62. [CrossRef]

20. Saleemi, J. An Empirical Analysis of Cost-Based Market Liquidity Measures for US \& Norwegian Banks. Master's Thesis, Universitetet i Nordland, Bodø, Norway, 2014.

21. PricewaterhouseCoopers. Global Financial Markets Liquidity Study; Technical Report, PwC; 2015. Available online: https:/ / www.pwc.se/sv / pdf-reports/global-financial-markets-liquidity-study.pdf (accessed on 1 November 2019).

22. Kunitsyna, N.; Britchenko, I.; Kunitsyn, I. Reputational risks, value of losses and financial sustainability of commercial banks. Entrep. Sustain. Issues 2018, 5, 943-955. [CrossRef]

23. Akerlof, G.A. The market for lemons: Quality uncertainty and the market mechanism. Q. J. Econ. 1970, 84, 488-500. [CrossRef]

24. Bagehot, W. The only game in town. Financ. Anal. J. 1971, 27, 12-14. [CrossRef]

25. Glosten, L.R.; Milgrom, P.R. Bid, ask and transaction prices in a specialist market with heterogeneously informed traders. J. Financ. Econ. 1985, 14, 71-100. [CrossRef]

26. Easley, D.; O’hara, M. Price, trade size, and information in securities markets. J. Financ. Econ. 1987, 19, 69-90. [CrossRef]

27. Oviedo-García, M.; Muñoz-Expósito, M.; Castellanos-Verdugo, M.; Sancho-Mejías, M. Metric proposal for customer engagement in Facebook. J. Res. Interact. Mark. 2014, 8, 327-344. [CrossRef]

28. Li, Z.; Li, C. Tweet or "re-tweet"? An experiment of message strategy and interactivity on Twitter. Internet Res. 2014, 24, 648-667. [CrossRef]

29. Kelly, L.; Kerr, G.; Drennan, J. Avoidance of advertising in social networking sites: The teenage perspective. J. Interact. Advert. 2010, 10, 16-27. [CrossRef]

30. Sawhney, M.; Verona, G.; Prandelli, E. Collaborating to create: The Internet as a platform for customer engagement in product innovation. J. Interact. Mark. 2005, 19, 4-17. [CrossRef]

31. Michaelidou, N.; Siamagka, N.T.; Christodoulides, G. Usage, barriers and measurement of social media marketing: An exploratory investigation of small and medium B2B brands. Ind. Mark. Manag. 2011, 40, 1153-1159. [CrossRef]

32. Sprenger, T.O.; Tumasjan, A.; Sandner, P.G.; Welpe, I.M. Tweets and trades: The information content of stock microblogs. Eur. Financ. Manag. 2014, 20, 926-957. [CrossRef] 
33. Larsson, A.O.; Moe, H. Studying political microblogging: Twitter users in the 2010 Swedish election campaign. New Media Soc. 2012, 14, 729-747. [CrossRef]

34. Hong, S.; Kim, S.H. Political polarization on twitter: Implications for the use of social media in digital governments. Gov. Inf. Q. 2016, 33, 777-782. [CrossRef]

35. Holmberg, K.; Thelwall, M. Disciplinary differences in Twitter scholarly communication. Scientometrics 2014, 101, 1027-1042. [CrossRef]

36. Vidya, N.A.; Fanany, M.I.; Budi, I. Twitter sentiment to analyze net brand reputation of mobile phone providers. Procedia Comput. Sci. 2015, 72, 519-526. [CrossRef]

37. Tetlock, P.C. Giving content to investor sentiment: The role of media in the stock market. J. Financ. 2007, 62, 1139-1168. [CrossRef]

38. Fang, L.; Peress, J. Media coverage and the cross-section of stock returns. J. Financ. 2009, 64, $2023-2052$. [CrossRef]

39. Luo, X.; Zhang, J.; Duan, W. Social media and firm equity value. Inf. Syst. Res. 2013, 24, 146-163. [CrossRef]

40. Chen, H.; De, P.; Hu, Y.J.; Hwang, B.H. Wisdom of crowds: The value of stock opinions transmitted through social media. Rev. Financ. Stud. 2014, 27, 1367-1403. [CrossRef]

41. Li, Q.; Chen, Y.; Wang, J.; Chen, Y.; Chen, H. Web media and stock markets: A survey and future directions from a big data perspective. IEEE Trans. Knowl. Data Eng. 2017, 30, 381-399. [CrossRef]

42. Nofsinger, J.R. Social mood and financial economics. J. Behav. Financ. 2005, 6, 144-160. [CrossRef]

43. Zhao, S.; Tong, Y.; Liu, X.; Tan, S. Correlating Twitter with the stock market through non-Gaussian SVAR. In Proceedings of the 2016 Eighth International Conference on Advanced Computational Intelligence (ICACI), Chiang Mai, Thailand, 14-16 February 2016; pp. 257-264.

44. Sul, H.; Dennis, A.R.; Yuan, L.I. Trading on twitter: The financial information content of emotion in social media. In Proceedings of the 2014 47th Hawaii International Conference on System Sciences, Waikoloa, HI, USA, 6-9 January 2014; pp. 806-815.

45. Ruan, Y.; Alfantoukh, L.; Durresi, A. Exploring stock market using twitter trust network. In Proceedings of the 2015 IEEE 29th International Conference on Advanced Information Networking and Applications, Gwangju, Korea, 25-27 March 2015; pp. 428-433.

46. Rakowski, D.A.; Shirley, S.; Stark, J. TwitTer Activity, Investor Attention, and the Diffusion Of Information. 2018. Available online: https://ssrn.com/abstract=3010915 (accessed on 1 November 2019).

47. Agrawal, S.; Azar, P.D.; Lo, A.W.; Singh, T. Momentum, Mean-Reversion, and Social Media: Evidence from StockTwits and Twitter. J. Portf. Manag. 2018, 44, 85-95. [CrossRef]

48. Liew, J.K.S.; Wang, G.Z. Twitter sentiment and IPO performance: A cross-sectional examination. J. Portf. Manag. 2016, 42, 129-135. [CrossRef]

49. Blankespoor, E.; Miller, G.S.; White, H.D. The role of dissemination in market liquidity: Evidence from firms' use of Twitter ${ }^{\mathrm{TM}}$. Account. Rev. 2013, 89, 79-112. [CrossRef]

50. Renault, T. Market Manipulation and Suspicious Stock Recommendations on Social Media. 2017. Available online: https:/ / ssrn.com/abstract=3010850 (accessed on 1 November 2019).

51. Al Guindy, M. Is Corporate Tweeting Informative or Is It Just Hype? Evidence from the SEC Social Media Regulation. 2016. Available online: https://ssrn.com/abstract=2824668 (accessed on 1 November 2019).

52. Ranco, G.; Aleksovski, D.; Caldarelli, G.; Grčar, M.; Mozetič, I. The effects of Twitter sentiment on stock price returns. PLoS ONE 2015, 10, e0138441. [CrossRef] [PubMed]

53. Smailović, J.; Grčar, M.; Lavrač, N.; Žnidaršič, M. Predictive sentiment analysis of tweets: A stock market application. In International Workshop on Human-Computer Interaction and Knowledge Discovery in Complex, Unstructured, Big Data; Springer: Berlin/Heidelberg, Germany, 2013; pp. 77-88.

54. Zheludev, I.; Smith, R.; Aste, T. When can social media lead financial markets? Sci. Rep. 2014, 4, 4213. [CrossRef] [PubMed]

55. Hasbrouck, J.; Seppi, D.J. Common factors in prices, order flows, and liquidity. J. Financ. Econ. 2001, 59, 383-411. [CrossRef]

56. Amihud, Y.; Mendelson, H. Asset pricing and the bid-ask spread. J. Financ. Econ. 1986, 17, $223-249$. [CrossRef]

57. Huang, R.D.; Stoll, H.R. The components of the bid-ask spread: A general approach. Rev. Financ. Stud. 1997, 10, 995-1034. [CrossRef] 
58. Corwin, S.A.; Schultz, P. A simple way to estimate bid-ask spreads from daily high and low prices. J. Financ. 2012, 67, 719-760. [CrossRef]

59. Mancini, L.; Ranaldo, A.; Wrampelmeyer, J. Liquidity in the foreign exchange market: Measurement, commonality, and risk premiums. J. Financ. 2013, 68, 1805-1841. [CrossRef]

60. Demsetz, H. The cost of transacting. Q. J. Econ. 1968, 82, 33-53. [CrossRef]

61. Ho, T.; Stoll, H.R. Optimal dealer pricing under transactions and return uncertainty. J. Financ. Econ. 1981, 9, 47-73. [CrossRef]

62. Ho, T.S.; Stoll, H.R. The dynamics of dealer markets under competition. J. Financ. 1983, 38, $1053-1074$. [CrossRef]

63. Brock, W.A.; Kleidon, A.W. Periodic market closure and trading volume: A model of intraday bids and asks. J. Econ. Dyn. Control 1992, 16, 451-489. [CrossRef]

64. Gorton, G.; Metrick, A. Haircuts. Fed. Reserve Bank St. Louis Rev. 2009, 92, 507-519.

65. Madrigal, V. Non-fundamental speculation. J. Financ. 1996, 51, 553-578. [CrossRef]

66. Brunnermeier, M.K.; Pedersen, L.H. Predatory trading. J. Financ. 2005, 60, 1825-1863. [CrossRef]

67. Copeland, T.E.; Galai, D. Information effects on the bid-ask spread. J. Financ. 1983, 38, 1457-1469. [CrossRef]

68. Roll, R. A simple implicit measure of the effective bid-ask spread in an efficient market. J. Financ. 1984, 39, 1127-1139. [CrossRef]

69. Będowska-Sójka, B.; Echaust, K. Commonality in Liquidity Indices: The Emerging European Stock Markets. Systems 2019, 7, 24. [CrossRef]

(C) 2019 by the authors. Licensee MDPI, Basel, Switzerland. This article is an open access article distributed under the terms and conditions of the Creative Commons Attribution (CC BY) license (http://creativecommons.org/licenses/by/4.0/). 